\title{
Time Series Analysis of Economic Growth, Environmental Conditions and Their Coordination Degree: A Case Study of Provinces in Northeast China
}

\author{
Mei Yang*, Yaojun Fan**†, Xiaoxue Zhang*(***) and Shoufeng Wu**** \\ *Institute of Educational Sciences, Comillas Pontifical University, Madrid 28080, Spain \\ **CHINA-ASEAN International College, Dhurakij Pundit University, Bangkok 10210, Thailand \\ ***Institute of Finance and Economics, Qinghai University, Xining 810000, China \\ ****Guizhou Radio and TV Station, Guiyang 550002, China \\ $†$ Corresponding author: Yaojun Fan: yaojun.fan@dpu.ac.th
}

\section{Nat. Env. \& Poll. Tech. \\ Website: www.neptjournal.com \\ Received: 16-04-2021 \\ Revised: 14-05-2021 \\ Accepted: 07-06-2021 \\ Key Words: \\ Regional economy \\ Population \\ Land use \\ GDP growth \\ Environmental investment}

\begin{abstract}
Northeast China is an old industrial base and agricultural production base with a long history of industrial and agricultural development. Since the beginning of the 21 st century, the contradiction between economic and social development and resource depletion and environmental damage has become increasingly acute due to the long-term extensive development model. Based on a long timeseries data set, this paper aims to explore the regional economic development model, environmental problems, and coordination degree between them in Northeast China. The results show that the population in Northeast China presents an increasing trend at first and then a decreasing one, and the population distribution shows an agglomeration in the cities of Harbin, Changchun, Shenyang, and Dalian. Urban-related land uses and GDP growth also exhibits agglomerations centered on these large cities. According to the changing trend of regional GDP and environmental investment, the synergistic relationship between the parameters is compared on a temporal scale, and a positive correlation between economic growth and environmental development is observed. We conclude that economic growth is closely correlated with environmental protection. If more attention is likely to be paid to environmental protection, the cities will develop more healthily under the background of urbanization. Based on the current status of the economy and environment, this paper puts forward constructive suggestions on promoting the coordinated development of regional economy and improving the ability of ecological environment governance. Improving the ecological environment's overall improvement capability through approaches such as adjusting the industrial structure, promoting the use of clean energy, strengthening industrial pollution control, controlling pollutant emissions, and promoting the construction of regional environmental infrastructure are all critical issues that must be resolved quickly to achieve coordinated development.
\end{abstract}

\section{INTRODUCTION}

The economy and the environment have a complex relationship, and economic development will inevitably result in ecological and environmental concerns. Globalization, dynamism, and integration are typical characteristics of this type of challenge, and environmental degradation is progressively becoming one of the elements impeding global development and human social progress. Exploring a harmonious relationship between the economy and the ecosystem is critical for developing a long-term economic development model and enhancing regional environmental governance capabilities (Liu et al. 2021, Xu et al. 2019, Zhang et al. 2020, Zhao et al. 2016). During the early stages of economic development, the government and businesses normally focus solely on economic growth. Mining and heavy industry, which are accompanied by excessive natural resource consumption, can successfully boost economic growth rates and become pillar industries in many local economies. However, the industry has an unnoticed impact on the natural equilibrium, resulting in ecological devastation and pollution, and so creating an imbalance between the environment, resources, and economic progress. Environmental issues will gradually improve as the economic model matures, the industrial structure is upgraded, and production technology advances. The relationship between economic development and the environment has been recorded in previous studies, with the environmental Kuznets curve being a commonly acknowledged economic model that reflects the inverted U-shaped link between environmental pollution and per capita income. According to the Environmental Kuznets Curve, when a country's economic development level is low, environmental pollution is light; as per capita income rises, environmental pollution rises, and the degree of environmental deterioration rises with 
economic growth; as economic development reaches a certain level, environmental pollution decreases from high to low, and the degree of environmental deterioration decreases with economic growth; as economic development reaches a certain level, environmental pollution decreases from high to low, and the degree of environmental. The notion of the relationship between environmental quality and income has been regularly studied, enriched, and improved since the introduction of the environmental Kuznets curve. Grossman \& Krueger (1995), for example, pointed out that economic growth has three effects on environmental quality: scale effect, technology effect, and structural effect. With the rapid development of the global economy and the deterioration of the environment in recent decades, experts have focused their attention on the relationship between the environment and economic development. In various areas and sectors, EKC curves were used to undertake the empirical study (Cantavella 2020, Chen \& Ieee 2008, Gill et al. 2019, Tzeremes 2019, Ying-Chun et al. 2021). The results show that in regions with different industrial structures and economic development patterns, the evolution of environmental pollution and economic growth presents different characteristics.

Since the 1980s, with China's fast industrialization and urbanization, economic expansion and population agglomeration have accelerated the plundering of natural resources, resulting in a slew of issues including pollution, resource depletion, and ecological degradation. These issues have posed significant obstacles to human existence and living situations, as well as stifled the country's and region's economic development, drawing the government's attention (Chen et al. 2010, Wang et al. 2020, Zhou et al. 2016). In recent years, one of China's national strategies has been the development of ecological civilization. Land, mineral, and petroleum resources abound in northeast China. The economy of this region began early, and a complete industrial system was constructed as early as the 1930s, making it Northeast Asia's most advanced industrial base. Northeast China has made significant contributions to China's economic development and government funding for more than half a century as the country's heavy industry base. However, due to the implementation of market-oriented reform in the 1990s, the economy of Northeast China has usually faced many difficulties, including the failure of firms and significant employment conflicts. Because of the advent of new sectors in those developed areas, the economic growth rate of Northeast China, which is dominated by conventional industries, has lagged substantially behind that of China's coastal cities in recent years. Furthermore, the long-term comprehensive development paradigm creates a growing conflict between economic and social development, resource depletion, and environmental degradation. Achieving coordinated develop- ment of ecological environment and social economy in this region is an important goal of regional development, and it is also the key to regional sustainable development.

The research objects in this study are the Heilongjiang, Jilin, and Liaoning provinces in Northeast China, which are being investigated for their coordinated development level between regional economy and environmental protection, against the backdrop of coupling changes in economy, land, and population. This article analyses the degree of coordinated growth of the economy and environment in Northeast China, and analyses the association between economic development speed and environmental investment, using the variation trend of some economic and environmental indicators during a 12-year period. The findings of this research will be useful in enriching and broadening environmental assessment research methodologies in the context of economic transformation and development, as well as providing a reference for regional industrial adjustment and policymaking.

\section{MATERIALS AND METHODS}

\section{Overview of the Study Area}

Northeast China is located in a temperate monsoon climate zone with four distinct seasons. The weather is hot and rainy in summer and cold and dry in winter. The landform in this area is mainly plain, with high forest coverage and abundant water and soil resources. Northeast China has a land area of 1.45 million square kilometers and a total population of 120 million. The geographical locations of the provinces of Heilongjiang, Jilin, and Liaoning are shown in Fig. 1. There is vast land suitable for cultivation in Northeast China, and the cultivated land area accounts for $20.6 \%$ of the national total. The soil in the northeast plain is fertile, and it is home to one of the world's three famous black land belts, which is ideal for agricultural cultivation and serves as China's main commodity grain source. Mineral resources abound in northeast China as well. Iron, manganese, and copper are the most common metal minerals, while coal, oil, and graphite are non-metal minerals. Northeast China's economy grew swiftly in the early years of the new China, thanks to abundant mineral resources and heavy industry. Northeast China's GDP accounted for more than $80 \%$ of the country's total in the 1950s. Although Northeast China is enriched in natural resources, a large number of non-renewable resources are consumed due to the long-term development of heavy industry, so many cities in Northeast China are now facing the problem of resource depletion.

\section{Description of Data Source and Statistical Methods}

The economic data and environmental indicators in this study come from the Chinese Urban Statistics Yearbook and the 


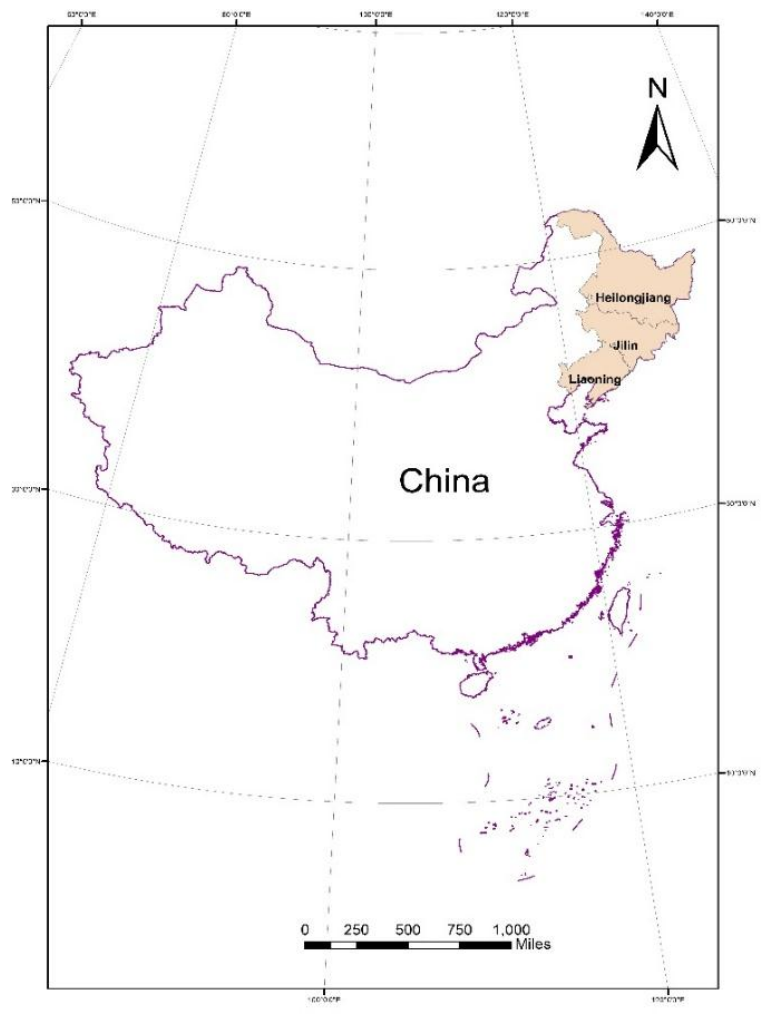

Fig. 1: Geographical location of provinces in Northeastern China: Heilongjiang, Jinlin and Liaoning.

Chinese Environmental Statistics Yearbook from 2004 to 2015. The spatial distribution maps of GDP, land use and population come from the Resource and Environment Science and Data Center of the Chinese Academy of Sciences.
The spatial distribution of GDP refers to the $\mathrm{km}$ grid data of GDP spatial distribution in the resolution of $1 \mathrm{~km}$ grid, which reflects the detailed spatial distribution of GDP data in the whole country (Ling et al. 2006). The distribution data of population is calculated by grid space, which combines the population number in unit weight with the total weight distribution map to spatialize the population. Statistical analyses were performed by IBM's statistical software Statistical Product and Service Solutions (SPSS 26).

\section{RESULTS AND DISCUSSION}

\section{Evolution of the Population and Land Uses of Provinces in Northeast China}

The trend of population variation in Liaoning, Jilin, and Heilongjiang from 2004 to 2015 is shown in Fig. 2. Before 2008 , the population of the three provinces showed an increasing annual trend, which was relatively stable from 2008 to 2010 and began to decline after 2010. The long-term low fertility level and the increase of net outflow population are the reasons for the population decrease in Northeast China. On the one hand, the population outflow in Northeast China is due to the decline of industrial bases, and the demand for personnel in energy and manufacturing industries, which are the pillars of the local economy, has decreased. On the other hand, the tertiary industry in developed cities in southern China is developing rapidly with large population demands. The salary in these cities is generally higher than that in Northeast China. Convenient high-speed rail transportation saves the transportation time for inter-provincial travel. These factors demonstrate a considerable desire among young people in

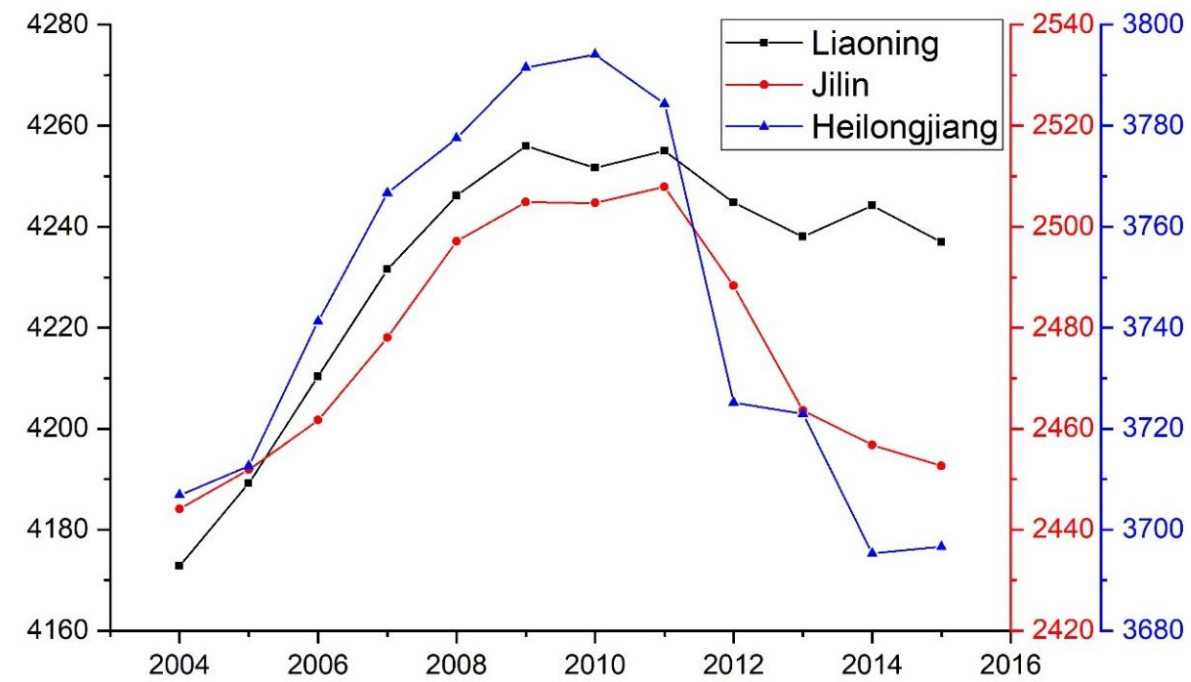

Fig. 2: The variation trend of the total population in Liaoning, Jilin, and Heilongjiang during the period of 2004-2015. 
Northeast China to work in the south. Heilongjiang is the province with the most population fluctuations, with a total population of 37.9405 million in 2010, but 36.9664 million in 2015, which is lower than in 2004. Because Heilongjiang is located on the Chinese-Russian border, its population movement may be linked to trade cooperation between the two countries. The population decrease in Liaoning from 2010 to 2015 is the least among the three provinces. Liaoning is located in the south of Northeast China, and it is close to the Beijing-Tianjin-Hebei economy, serving as the gateway to the opening up of Northeast China. In comparison to the other two provinces, Liaoning has substantial geographic and economic advantages, as well as the ability to absorb population inflow. Northeast China has a low population density. Because of the low population density, the scale of population outflow continues to expand, and population growth is modest, posing a greater threat to regional development.

The evolution of population distribution in northeast China during a 10-year period is shown in Fig. 3. Spatially, the overall population distribution characteristics did not change significantly from 2005 to 2015 . The densest population appeared in four large cities (Harbin, Changchun, Shenyang, and Dalian) and their surrounding areas, while the population in northern Heilongjiang Province with higher latitude was the rarest. The center of population hot spots shows a trend of gathering from north to south, indicating that the region's population movement is from north to south. Between 2010 and 2015, Liaoning Province saw a variety of population gathering places emerge, with Dalian and Shenyang having the highest population density. In Liaoning, the urban distribution is defined by a double-center structural pattern. Liaoning is home to two megacities: Shenyang and Dalian. Shenyang is the provincial capital and a famous heavy industry base in China, while Dalian is a famous port city in North China and a window of foreign trade in Northeast China. These two cities have become the main inflow places of population movement in Northeast China and are also the centers of Liaoning's economy, whose regional GDP accounts for over $50 \%$ of the province's total. Industrial agglomeration makes these two regions have concentrated jobs and higher income levels, attracting young people to flow in and thus bringing about population agglomeration.

Fig. 4 depicts the spatial characteristics of land use categories in Northeast China in 2005, 2010, and 2015. Land use statistics based on Landsat 8 are separated into agricultural and forestry land, urban and industrial land, and unused land to better comprehend the relationship between potential environmental problems and human activities. The share of urban-related land in Northeast China is progressively increasing, similar to the developing trend of land use in other parts of China. Three urban agglomerations centered on central and southern Liaoning, central Jilin, and central Heilongjiang has gradually formed and expanded in Northeast China. However, the connectivity among the three urban agglomerations is weak. Compared with the urban agglomerations in developed provinces in China (such as Yangtze River Delta, Pearl River Delta, and Chengdu-Chongqing City Circle), there is a huge gap in the scale of urban agglomerations. Large cities are not able to gather resources and drive the development of surrounding cities. Northeast China is also characterized by an imbalanced level of urbanization and industry within the region. Shenyang, Dalian, Chang-
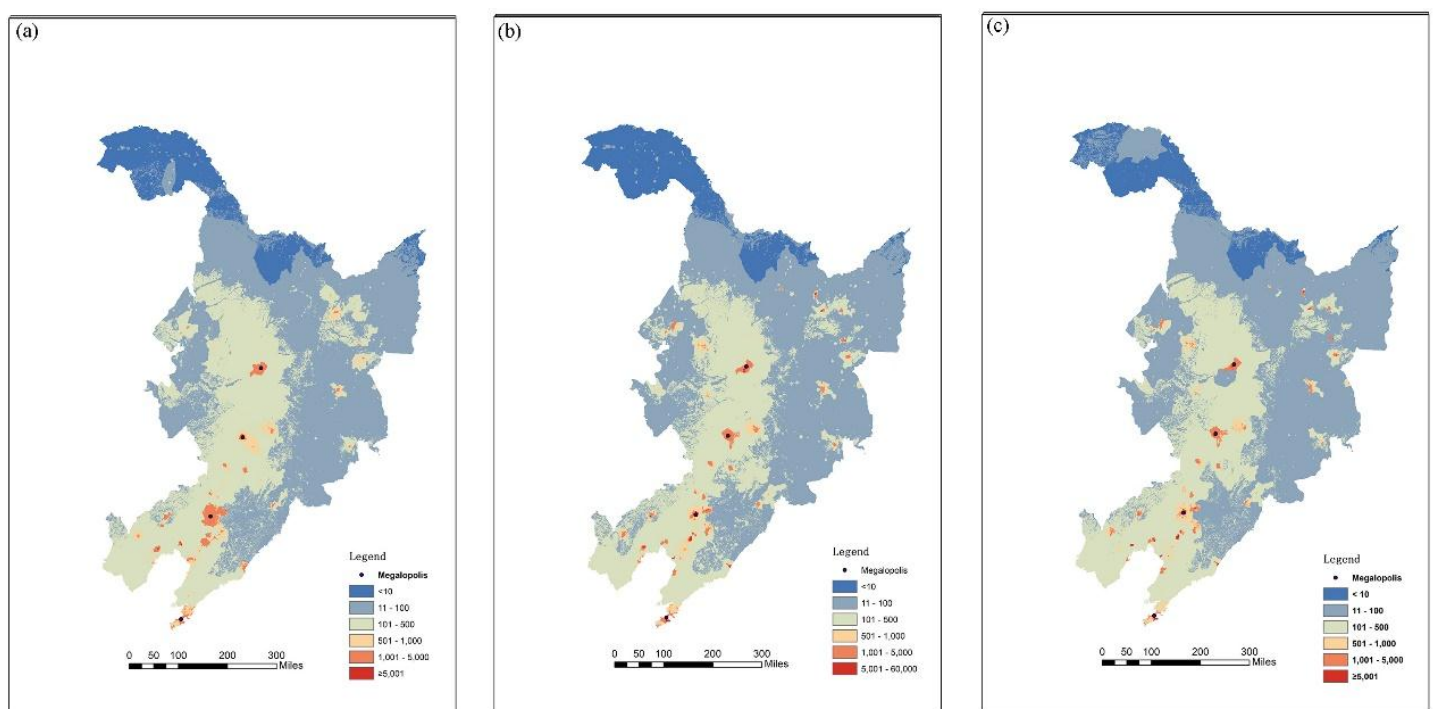

Fig. 3: Evolution of the population density in Northeast China during the ages of (a) 2005, (b) 2010, and (c) 2015. 

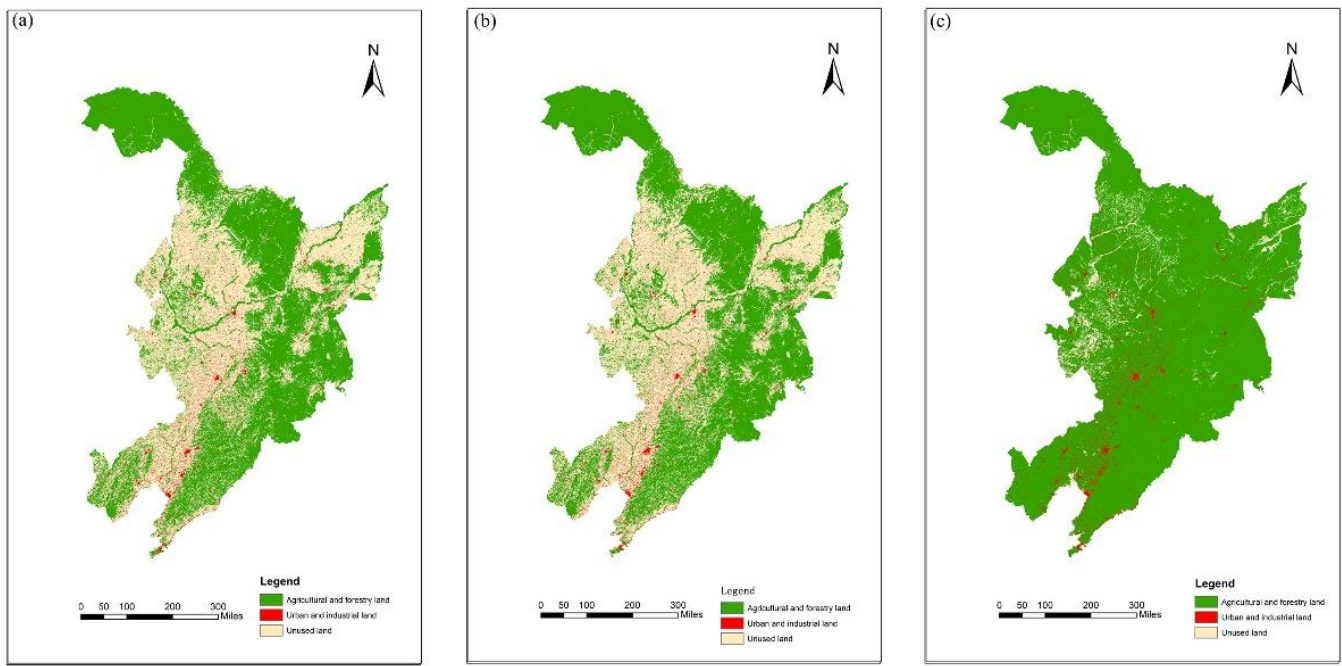

Fig. 4: Spatial variation in land-use types in Northeast China through a time span of 2005 to 2015. The green spots represent the land uses related to agriculture and forestry, the red ones represent those related to urban activities, and the yellow ones represent unused land.

chun, and Harbin, as well as their surrounding districts, saw the largest expansion of urban and industry-related land, which is consistent with the trend of population agglomeration shown in the preceding section. Large cities are faced with the problems of over-concentration of population and industry, while the county economy is backward, the town scale is small, the infrastructure is undeveloped, the industrialization foundation is weak, and urbanization is a typical urban-rural dual structure. This makes the environmental quality of large cities in Northeast China decline, and the ecological destruction is prominent, while the economic development momentum of small and medium-sized cities is insufficient.

\section{Development of the GDP Growth in Northeast China}

By comparing the $\mathrm{km}$ grid data sets of GDP spatial distribution in 2005, 2010, and 2015, the spatial pattern and evolution law of economic development in Northeast China are reflected (Fig. 5), and each grid represents the GDP within 1 square kilometer. It can be observed that the economic development of coastal cities in the south of Northeast China is relatively fast, while that of coastal cities in the north is
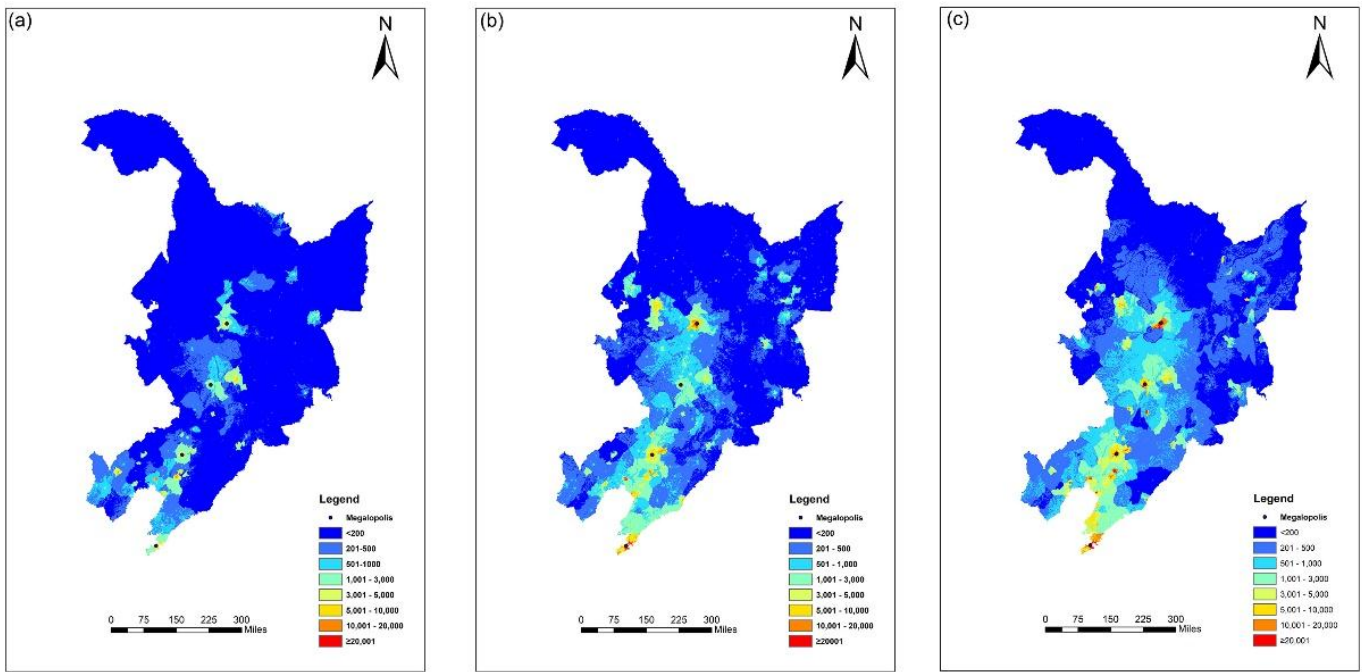

Fig. 5: Distribution of GDP per capita in provinces of Northeast China in the ages of (a) 2005, (b) 2010, and (c) 2015. 
much slower. With the improvement of economic level, the agglomeration trend around Dalian, Shenyang, Changchun, and Harbin is further strengthened, and the spatial differences of regional economic development are increasing. The spatial differentiation of economic development level in Northeast China has a great relationship with its natural factors, traffic location, and the dependence and development degree of early mineral resources. The economic growth of resource-based cities and traditional industrial cities (e.g., Hegang, Panjin, Anshan, Baishan, and Daqing) slows down, which is mainly influenced by many factors such as industrial structure, human capital, technological progress, and system improvement. Because mineral resources are unsustainable, cities that rely on mining as a major source of revenue will inevitably undergo a downturn. The output of resources is rapidly reduced in these cities as a result of long-term continuous exploitation, a large number of connected firms are closed and bankrupt, environmental degradation is severe, and the number of unemployed people rises sharply.

\section{Principal Environmental Problems in Northeast China}

The environmental problems in Northeast China are outstanding, the environmental quality is gradually deteriorating, and the carrying capacity of resources and environment is facing challenges, which has greatly bound the economic development in Northeast China. The main environmental problems in Northeast China can be divided into the following three types:

(1) Environmental problems caused by industrial development. In recent hundred years, large-scale development has seriously deteriorated the ecological environment in Northeast China, and the problems are increasingly prominent. Before 1949, colonists from Japan and Russia plundered a large amount of iron ore, coal, and other forest resources, which led to great damage to resources and the ecological environment in Northeast China. Since the 1950s, Northeast China, as an old industrial base in China, has carried out large-scale industrial development to achieve the urgent demand of rapid economic development. In addition, the pollution control level seriously lagged, which caused extremely high resource consumption in Northeast China and make the ecological environment seriously deteriorate. At present, the proportion of heavy industry in the industrial structure of Northeast China is too large, and this feature has not been completely changed, which increases the utilization of natural resources and the pollution of the ecological environment.

(2) Environmental problems caused by agricultural and forestry activities. As one of the most suitable agricultural areas for cultivation, Northeast China plays an important role in crop production in China all along. The large-scale agricultural land reclamation in Northeast China has changed the grassland landscape, resulting in serious vegetation destruction, land desertification, and salinization. Due to the over-reclamation, more than half of the cultivated land suffered serious soil erosion and fertility decline. The natural wetlands are greatly shrunk and degraded, and their ecological functions are seriously impaired. In addition, Northeast China is the largest timber production base in China. Longterm imbalance of harvesting and compensation and deforestation have reduced the area of natural forests and weakened the ecological functions of forests.

(3) Pollution of the air and water in huge cities. With the growth of cities and the concentration of population, resource scarcity, pollution, and ecological degradation are frequent elements that stifle urban development. In large cities such as Harbin, Changchun, Shenyang, and Dalian, the exhaust pollution caused by the increase in the number of motor vehicles is increasing, and the air pollution results from the smoke and industrial dust emitted by coal-burning (especially in the winter heating period) is becoming serious. As most polluting industries in Northeast China are located in dense urban areas, concentrated sewage makes rivers polluted.
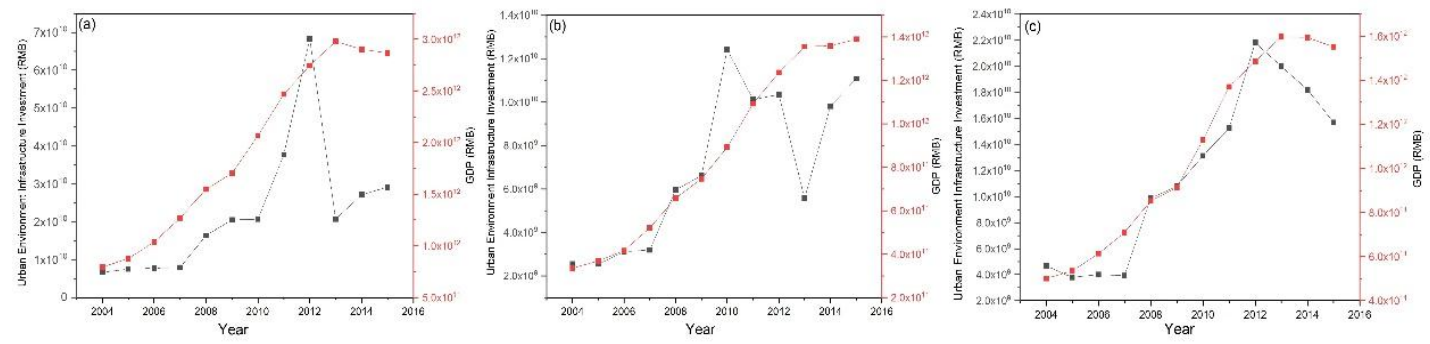

Fig. 6: Variation trend of GDP growth and Investment in Urban Environment Infrastructure during the period of 2004 to 2015 in (a) Liaoning, (b) Jilin and (c) Heilongjiang. 


\section{Coordination Degree Between Economic Growth and Environment}

Coordinated development of economy and environment is a necessary condition for achieving sustainability, and it is also an important issue in regional development. Coordinated development should aim at reaching the all-around development of human beings, and form a virtuous circle of social development through the cooperation and promotion among the subsystems of population, society, economy, science, and technology, environment, and resources in the region. Investment in Urban Environment Infrastructure (IUEI) is mainly from the local finance and government-induced social capital, aiming to promote the environmental quality in urban regions. The investment is used in areas of gas supply, central heating, sewage projects, gardening \& greening, sanitation, and garbage treatment. It demonstrates both the local government's financial capabilities and its commitment to environmental betterment. To evaluate the coordination degree between economy and environment in Northeast China, the changing trend of GDP and IUEI from 2004 to 2015 is shown in Fig. 6. The total GDP and per capita GDP of Liaoning Province are both the highest in Northeast China. From 2004 to 2010, the GDP of Liaoning Province increased rapidly, but the growth rate of IUEI was slow, which may be because local policies attached importance to economic development and ignored environmental protection; from 2010 to 2012, the investment in urban environmental facilities in Liaoning Province increased rapidly; after 2012, the IUEI showed a decreasing trend. In Jilin and Heilongjiang, IUEI was relatively fixed from 2004 to 2007; after the year 2007, IUEI and GDP grew rapidly simultaneously, showing a high degree of coordination, which shows that local governments increased the proportion of environmental protection budget in finance and increased financial support for environmental protection in the process of economic growth with the rapid economic growth and the country's emphasis on environmental protection. However, after the year of 2012, all three provinces experienced stagnation or even negative growth in GDP, and IUEI also experienced a significant decline. In Liaoning province, IUEI dropped sharply from 68.34 billion in 2012 to 20.34 billion in 2013 and then remained stable. In Jilin Province, IUEI experienced a sudden decline in 20122013 and then gradually picked up. In Heilongjiang Province, IUEI decreased by $8 \%-15 \%$ yearly after 2012 . The presented trends show that there is a significant positive correlation between economic growth and environmental investment. In a period of rapid economic growth, the coordination between economy and environment is high. The stagflation or recession of the economy has a serious negative impact on environmental protection, but the degree of negative impact is also controlled by the local government's emphasis on environmental governance.

\section{Suggestions for Improving the Coordinated Development of the Economy and Environment}

The stagnation and recession of economic development are important factors hindering environmental governance. Currently, the heavy industry still accounts for a large proportion of the regional economy of Northeast China. However, the surplus of energy production leads to the development of resource-concentrated enterprises in trouble in the current development stage of China, and the industrial model dominated by heavy industry has a great hindrance to the development of the ecological economy. Therefore, it is urgent to upgrade the industrial structure, accelerate the industrial transformation, and develop strategic new industries and high-tech industries in Northeast China, to solve the industrial pollution problems in the development of industrial enterprises and promote the coordinated development of the environment and economy. To achieve the virtuous circle of the ecological environment during the process of economic growth and promote sustainable development, it is important to improve the comprehensive improvement ability of the ecological environment by approaches of adjusting the industrial structure, promoting the use of clean energy, strengthening industrial pollution control, controlling pollutant emissions and promoting the construction of regional environmental infrastructure.

On the other hand, the higher urbanization development stage will be accompanied by the population explosion in large cities, and the ecological carrying capacity will be under great pressure. It is a strategy for alleviating population, resource, and environmental pressures on large cities by encouraging the development of nearby villages and towns and promoting the integration of urban and rural areas. Therefore, accelerating the construction of transportation and township infrastructure, forming a fast railway, highway, waterway, and air transportation network, and thus accelerating the radiation of the center to the surrounding small and medium-sized cities and towns will be effective means to alleviate the environmental pollution of urban agglomerations.

\section{CONCLUSION}

Based on a 12-year long time-series data set, this paper introduces the economic development and environmental characteristics of Liaoning, Jilin, and Heilongjiang provinces in Northeast China, and analyzes the coordination degree of 
economy and environment in this region through the temporal variation trends of GDP and IUEI. The trends of population agglomeration and urban expansion in Northeast China are centered on four large cities of Harbin, Changchun, Shenyang, and Dalian, and spreads to surrounding areas, which is consistent with the spatial pattern and evolution trend of regional economic growth. The main environmental problems in North China include long-term resource exploitation and industrial production, excessive agricultural reclamation and deforestation, and concentrated pollutant emission in urban areas. During the study period, the economy in Northeast China transited from the rapid growth stage to the stagflation recession stage due to the recession of industry and mining and the prominent problem of overcapacity. There is a positive feedback relationship between economic growth and the government's environmental investment, and the sluggish or declining economic situation will inevitably lead to the shortage of environmental governance funds. The most essential means of solving environmental problems in the process of urban expansion and promoting the coordinated development of the environment and economy is to follow a sustainable economic development pattern. On the one hand, provinces in Northeast China should urgently speed up the optimization and upgrading of industrial structure, reduce the proportion of high-pollution heavy industrial enterprises in the regional economy, attach importance to the development of emerging industries, and control the generation and emission of environmental pollutants from the source; On the other hand, urban agglomerations centered on four large cities should be taken as the main body to promote regional urbanization and thus ease the ecological environment pressure faced by large cities.

\section{REFERENCES}

Cantavella, M. 2020. The role of services in the environmental Kuznets curve for Spain. Econ. Bus. Lett., 9(4): 326-333.

Chen, M., Lu, D. and Zha, L. 2010. The comprehensive evaluation of China's urbanization and effects on resources and the environment. J. Geogr. Sci., 20(1): 17-30.

Chen, W. and Ieee, M. 2008. An empirical test on the environmental Kuznets Curve hypothesis in China. China Econ. Rev., 19(3): 381-392.

Gill, A.R., Hassan, S. and Viswanathan, K.K. 2019. Is democracy enough to get the early turn of the environmental Kuznets curve in ASEAN countries? Energy Environ., 30(8): 1491-1505.

Grossman, G.M. and Krueger, A.B. 1995. Economic growth and the environment. Q. J. Econ., 110(2): 353-377.

Ling, Y.I., Xiong, L.Y. and Yang, X.H. 2006. Method of pixelizing GDP data based on the GIS. J. Gansu Sci., 6: 71-89.

Liu, K., Qiao, Y., Shi, T. and Zhou, Q. 2021. Study on coupling coordination and spatiotemporal heterogeneity between economic development and ecological environment of cities along the Yellow River Basin. Environ. Sci. Pollut. Res., 28(6): 6898-6912.

Tzeremes, P. 2019. Does the environmental Kuznets Curve exist in the Chinese region? Glob. Econ. Rev., 48(4): 363-377.

Wang, Y., Geng, Q., Si, X. and Kan, L. 2020. Coupling and coordination analysis of urbanization, economy, and environment of Shandong Province, China. Environ. Develop. Sustain., 31(11): 234-249

Xu, M., Chen, C. and Deng, X. 2019. Systematic analysis of the coordination degree of China's economy-ecological environment system and its influencing factor. Environ. Sci. Pollut. Res., 26(29): 29722-29735.

Ying-Chun, L., Yuan-Ying, C., Xiao-Ru, N., Xiang-Dong, L. and Rui, P. 2021. Kuznets Curve based analysis on the relationship between economic growth and environmental quality in Beijing. IOP Conference Series: Materials Science and Engineering, 1043: 022009

Zhang, W., Zhang, X., Zhang, M. and Li, W. 2020. How to coordinate economic, logistics and ecological environment? Evidence from 30 provinces and cities in China. Sustainability, 12(3): 14-27.

Zhao, F., Zhang, W. and Zhang, C. 2016. quantifying the coordination of energy development and environmental protection: A case study of China. Energy Proc., 104: 520-525.

Zhou, M., Zhao, X.L. and Huang, L. 2016. The Effects of Urbanization on the Environment Pollution in China. Int. Conf. Elect. Inform. Computer Eng., 44: 2047-2051. 